\title{
The Investigation on Physical Education Teacher Candidate's Resilience, Tenacity and Motivation Levels
}

\author{
İsmail ÇELİK ${ }^{1}$ \\ Serkan T. AKA ${ }^{2}$ \\ Fehmi ÇALIK ${ }^{3}$ \\ Gökhan BAYRAKTAR ${ }^{4}$ \\ Metin BAYRAM ${ }^{5}$
}

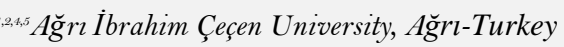

Sakarya University, Sakarya, Turkey

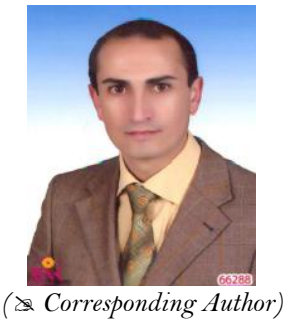

( Corresponding Author)

\begin{abstract}
The main purpose of this study is to examine possible relationships between resilience, tenacity and motivation of physical education teacher candidates. In addition, resilience, tenacity and motivation levels were examined according to class and gender levels. Participants of the study are 154 PE students in Ağrı province. There are 50 female participants and 104 male students. The Resilience Scale adapted to Turkish by Sarıçam et al. (2012). The Tenacity Scale-Short Form adapted to Turkish by Sarıçam et al. (2016) Stability Scale and Personal Information Form were used. To analyze the data, t test, ANOVA, Pearson moment product correlation analysis and multiple regression analysis were used. $99 \% \mathrm{p}<.01$ was taken as confidence interval in the study. According to research findings, there are statistically significant relationships in positive direction among the resilience, tenacity and motivation in the candidates of physical education teachers. When the resilience increases, tenacity and motivation levels also increase. According to gender and class level, resilience, tenacity and motivational stability do not differ statistically. The study can be expanded by adding different sections and classes.
\end{abstract}

Keywords: Physical education, Resilience, Tenacity and motivation.

Citation | İsmail ÇELIKK; Serkan T. AKA; Fehmi ÇALIK; Gökhan BAYRAKTAR; Metin BAYRAM (2018). The Investigation on Physical Education Teacher Candidate's Resilience, Tenacity and Motivation Levels. Journal of Education and e-Learning Research, 5(3): 174-178.

History:

Received: 14 February 2018

Revised: 21 June 2018

Accepted: 7 August 2018

Published: 10 October 2018

Licensed: This work is licensed under a Creative Commons

Attribution 3.0 License (c) $\mathbf{E Y}$

Publisher: Asian Online Journal Publishing Group
Contribution/Acknowledgement: All authors contributed to the conception and design of the study.

Funding: This study received no specific financial support.

Competing Interests: The authors declare that they have no conflict of interests.

Transparency: The authors confirm that the manuscript is an honest, accurate, and transparent account of the study was reported; that no vital features of the study have been omitted; and that any discrepancies from the study as planned have been explained.

Ethical: This study follows all ethical practices during writing.

\section{Contents}

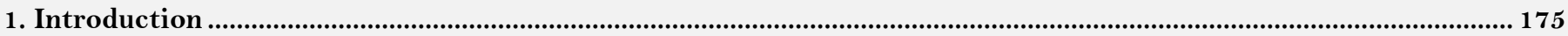

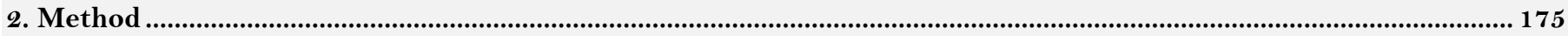

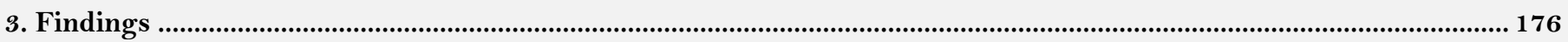

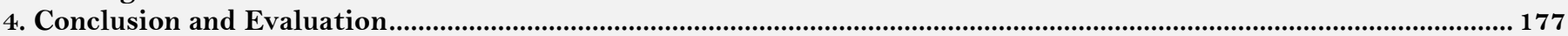

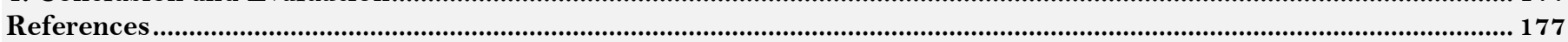




\section{Introduction}

Knowledge, skills, competences and attitudes are needed in the cognitive, emotional and dynamic areas in order to be able to produce in the teaching profession as it is in every profession. These characteristics can also be taken within the scope of individual responsibilities that the individual acquires from the other side at the point of personal development while trying to acquire them together with the courses taken during undergraduate education. . Teachers, like every profession, want to accommodate qualities that can make them strong at the point of their work. At the beginning of these properties is the resilience.

Resilience, is a rapid recovery capacity and tendency despite of the negative life experiences and stressors encountered, Sarıçam et al. (2012); Sarıçam and Yetim (2016). According to Rutter (2006) achieving strong output in risk and stress factors is reducing vulnerability to surrounding challenges and obstacles. In another definition, it is a strong fit against the changes that individuals may face in the face of unfavorable situations and the changes that may occur in their lives (Karairmak, 2006). Resilience that manifests itself in the form of continuous mood, adaptation, internal control, sense of humor, Masten (1986); Karairmak (2006) is of great importance in terms of teaching profession, which is called art of human reproduction. Physical education and sports teacher candidates are considered to be a feature that robustly completes the state of being physically solid.

One is a powerful character and another is a tenacity. In other words, tenacity is one of the signs of character power. Individuals with high self-control have high levels of tenacity. There are processes that require decisions in every human life. It is important to insist on reaching the result of the decision as much as the strategies used in decision making. Duckworth et al. (2007) call for tenacity to show the extreme desire, effort, and determination to overcome obstacles the individual will face. When it is thought that education is a long process, there is a need for teacher and teacher candidates to continue this process (Celik, 2015; Sarıçam et al., 2016).

Ahmet et al. (2015) the concept of motivation (Breen and Lindsay, 2002; Brennen, 2006; Pew, 2007; Demirel, 2009; Soyer et al., 2010; Calik, 2014) which appears to be a desire to be successful in the educational process, manifests itself in two forms as internal and external motivation (Ryan and Deci, 2000) but the most effective is internal motivation (Deci and Ryan, 1985). Motivational stability is one of the goal orientated personality traits (Bostan, 2015) and is an important element for quality learning and success (Saricam et al., 2014). In our lives, we will have long-term goals and ideals in which we can have short-term goals. Motivational stability is inevitable especially for long-term goals (Sariçam, 2015).

\subsection{The Aim and Importance of the Study}

After the emergence of positive psychology in the last quarter of the twentieth century, it is inevitable that today this current reflects on different disciplines such as management, business, economy, sports and education. One of the most important aims of positive psychology is the components of goodness and how this will be achieved.) according to PERMA-Profile, which has developed to evaluate the state of well-being. These are positive emotions, attachment, relationships, meaning and success. As you can see, one of the elements that lead to the subjective well-being of the individual is success. Thus, identifying the factors that make a student successful in a sport, in a teacher, will provide significant contributions in showing the reflection of positive psychology on the educational discipline.

The main purpose of this study is to examine possible relationships between resilience, tenacity and motivation of prospective physical education teacher candidates. Furthermore, it is accepted that the study of resilience, tenacity and motivation levels according to class and gender levels may provide teacher candidates with cognitive and emotional readiness to carry out their future professions together with qualification in the dynamic area. For this reason, it will be possible to eliminate deficiencies and program deficiencies according to the research results.

\section{Method}

\subsection{Study Group}

Participants of the study are 154 PE and Sports students in Ağrı province. There are 50 female participants and 104 male students. Participants' ages ranged from 20 to 25 years, with a mean age of $21.51(\mathrm{Ss}=1.22)$.

\subsection{Data Collection Tools}

For the purpose of data collection in the study, Resilience Scale adapted to Turkish by Sarıçam et al. (2012) Motivational (Turkish) adapted to Turkish culture by Saricam et al. (2014) Azim Scale-Short Form adapted to Turkish by Sarıçam, Çelik and Oğuz Stability Scale and Personal Information Form were used.

Resilience Scale: Confirmatory factor analysis result 12 items 3 factorial constructs fit index values $\chi^{2}=$ 117.28, $\mathrm{sd}=47, \mathrm{p}=0.00000, \mathrm{RMSEA}=.060$, CFI $=.97$, NFI $=.95, .97$, GFI $=.96$, SRMR $=.049$ ). The factor loadings are in the range of .38 to .70 . Cronbach alpha internal consistency reliability coefficients were found to be .66 for social support, .73 for emotional coping, .71 for situational coping, and .81 for the entire scale. Corrected item total correlations range from .38 to .57 .

Tenacity Scale-Short Form: In the explanatory factor analysis, it was observed that the scale items were in original form under 2 factor after being found that the sample suitability and number were sufficient in the results of the KMO sample suitability coefficient .83 and the Bartlett-Sphericity test $\chi^{2}=503,877(\mathrm{p}<.001$, sd $=24)$. The AFA endurance factor loadings ranged from .46 to .65 for the subscale of relevance and .67 to .80 for the vigorous insistence subscale. Furthermore, these two sub-dimensions explain $53 \%$ of the total variance. The validity factor analysis results showed that the fit index values of the 2 -dimensional model of 8 items $\left(\chi^{2} / \mathrm{sd}=2.06, \mathrm{p}=.00011\right.$, $\mathrm{RMSEA}=.046, \mathrm{CFI}=.95, \mathrm{GFI}=.94, \mathrm{AGFI}=.93, \mathrm{SRMR}=.047)$; factor loadings ranged from .42 to .77 . In the similar scale validity study, the relationship between $\mathrm{r}=.68 \mathrm{p}<.01$ was found between Motivational Stability Scale and Short Stability Scale. Internal consistency: The Cronbach alpha internal consistency reliability coefficients were calculated as .83 for the whole scale, .80 for the interest coherence subscale, and .71 for the vigor persistence 
subscale. The test re-test correlation coefficient was calculated as .86 with 64 people in the same study group with 21 days intervals.

Motivational Stability Scale: The fit index values were found $(\chi 2=141.85, \mathrm{sd}=60, \mathrm{RMSEA}=.058, \mathrm{CFI}=$ $.85, \mathrm{GFI}=.95, \mathrm{AGFI}=.92 \mathrm{SRMR}=.057)$ for the DFA result three-dimensional model applied for construct validity of the Motivational Stability Scale. The factor loadings of the scale ranged from .30 to .61. The Cronbach Alpha internal consistency reliability coefficient of the Motivational Stability Scale was 0.69 for the overall scale, .72 for the long-term goals follow-up subscale, .70 for the current targets follow-up subscale, and .71 for the unreachable goals repeatability subscale. In addition, when the scale was re-administered to 73 subjects from the same study group after 26 days for a test-retest reliability scale, the correlation coefficient between the two applications was $\mathrm{r}=.66$ for the whole scale, $\mathrm{r}=.69$ for the long-term targets follow-up sub-dimension, $\mathrm{r}=.70$ for unreachable targets and $r=.68$ for replicate sub-dimensions.

\subsection{Process}

In data obtained from 3 scales obtained from Ağrı İbrahim Çeçen University Physical Education and Sports School students, 19 data which distorted the normal distribution were taken and Pearson moments multiplication correlation analysis, multiple regression analysis, $\mathrm{t}$ test and ANOVA test were used from parametric tests to analyze the data obtained from 154 participants. $99 \% \mathrm{p}<.01$ was taken as confidence interval in the study.

\section{Findings}

Findings were obtained in three different chapters and tried to be explained in tabular form as findings related to sex, findings related to class level and correlation findings.

\subsection{Findings Related to Sex}

Independent samples $t$ test was used to determine whether the resilience, tenacity and motivation levels of the candidates for physical education teacher candidates differ according to the sex, and the findings are shown in Table 1.

\begin{tabular}{|c|c|c|c|c|c|c|}
\hline Variable & Gender & $\mathbf{N}$ & $\bar{X}$ & SS & $\mathrm{t}$ & $\mathbf{p}$ \\
\hline \multirow[t]{2}{*}{ Resilience } & Female & 50 & 43,72 & 6,94 & \multirow[b]{2}{*}{-.72} & \multirow{2}{*}{.47} \\
\hline & Male & 104 & 44,65 & 8,41 & & \\
\hline \multirow[t]{2}{*}{ Motivation } & Female & 50 & 48,48 & 9,39 & \multirow{2}{*}{1.61} & \multirow{2}{*}{.11} \\
\hline & Male & 104 & 45,96 & 8,21 & & \\
\hline \multirow[t]{2}{*}{ Tenacity } & Female & 50 & 25,76 & 3,47 & \multirow{2}{*}{1.45} & \multirow{2}{*}{.15} \\
\hline & Male & 104 & 26,67 & 3,87 & & \\
\hline
\end{tabular}

Source: Data have obtained from authors' field study.

As seen in Table 1, the average of the resilience scores of women $(=43.72)$ is lower than the average of the resilience scores of men $(=44.65)$; this difference was not statistically significant $(t=-.72, p>.05)$. In terms of motivation levels, the average score of the women $(=48.48)$ and the motivation of the men were found to be 3887.50 , but this was not statistically significant $(\mathrm{t}=1.61, \mathrm{p}>.05)(\mathrm{T}=1.45, \mathrm{p}>.05)$, although this score was found to be higher than that of women (26.67). As a result, resilience, tenacity and motivation levels of physical education teacher candidates do not differ statistically according to sex.

\subsection{Findings Related to Class Level}

One-way ANOVA was applied to determine whether the resilience, tenacity and motivation levels of the physical education teacher candidates differ according to the class level and the findings are shown in Table 2.

Table-2. One-way ANOVA results of comparison of resilience, tenacity and motivation levels of physical education teacher candidates by class level

\begin{tabular}{l|l|c|c|c|c|c}
\hline Variable & Sum of Square & sd & Average of squares & F & p \\
\hline \multirow{2}{*}{ resilience } & Inter-group & 33,786 & 3 & 11,262 &, 176 &, 913 \\
\cline { 2 - 7 } & Intra-group & 9219,322 & 144 & 64,023 & \\
\cline { 2 - 7 } & Total & 9253,108 & 147 & & \\
\hline \multirow{2}{*}{ Mot. } & Inter-group & 21,568 & 3 & 7,189 &, 094 &, 963 \\
\cline { 2 - 7 } & Intra-group & 11041,135 & 144 & 76,675 & \\
\cline { 2 - 7 } & Total & 11062,703 & 147 & &, 381 \\
\hline \multirow{2}{*}{ Tenacity } & Inter-group & 43,482 & 3 & 14,494 & & \\
\cline { 2 - 7 } & Intra-group & 2026,815 & 144 & 14,075 & & \\
\cline { 2 - 7 } & Total & 2070,297 & 147 & & & \\
\hline
\end{tabular}

Source: Data have obtained from authors' field study.

As seen in Table 2, the resilience scores of the physical education teacher candidates do not differ statistically according to the grade level $(\mathrm{F}(3,147)=.18, \mathrm{p}>.05)$. Stability scores did not differ statistically according to class level $(\mathrm{F}(3,147)=1.03, \mathrm{p}>.05)$. The motivation stability levels did not differ statistically according to the grade level $(\mathrm{F}(3,147)=1.03, \mathrm{p}>)$.

\subsection{Correlation Findings}

Pearson moment product correlation analysis was applied to determine whether there was a relationship between resilience, tenacity and motivation levels in the candidates for physical education teachers and the findings are shown in Table 3. 
Table-3. Results of Pearson Correlation Tests Relating Resilience, Tenacity and Motivation Levels

\begin{tabular}{l|c|c|c|c|c|c}
\hline Variable & $\mathbf{1}$ & $\mathbf{2}$ & $\mathbf{3}$ & $\overline{\mathrm{X}}$ & $\mathbf{S s}$ & $\boldsymbol{\alpha}$ \\
\hline 1.Resilience & - & $.69^{* *}$ & $.22^{* *}$ & 44.34 & 7.93 & .84 \\
\hline 2.Motivation Stability & & - & $.31^{* *}$ & 46.81 & 8.67 & .76 \\
\hline 3.Tenacity & & & - & 26.36 & 3.75 & .88 \\
\hline *** $<.01$
\end{tabular}

There is a statistically significant positive correlation between resilience and motivational stability at the $\mathrm{p}$ $<.01$ significance level $(r=.61)$. There was a statistically significant positive correlation between resilience and tenacity at $\mathrm{p}<.01$ significance level $(\mathrm{r}=.22)$. There was a statistically significant positive correlation between motivation and tenacity at the $\mathrm{p}<.01$ significance level $(\mathrm{r}=.31)$.

\section{Conclusion and Evaluation}

The main reason for this study was to determine the relationship between resilience, tenacity and motivational stability levels in physical education teacher candidates. According to research findings, tenacity level increases when resilience is increased. Celik et al. (2018) found that increasing their beliefs about the strengths of individuals increases their resilience and their psychological stability increases their tenacity. Celik and Sarıçam (2018) found that their positive thinking skills increased little by little. So the above studies overlap with the study findings.

In another finding of the study, a positive relationship was found between resilience and motivational stability. In other words, when the resilience is increased, the effort and insistence of the individual in achieving success are also increasing. Sarıçam and Kırgıl (2013) stated that as the well-being of teachers increases, their motivational commitment increases. Conscious awareness plays an important role in the formation of the psychological integrity that comes from the overcoming of difficulties (Keye and Pidgeon, 2013). When individuals increase their conscious awareness, the motivation to achieve their goals is also increasing (Raphiphatthana et al., 2018). These current findings support this research finding.

In another finding of the study, statistically significant relationship was found between tenacity and motivational stability. Similarly, Reraki et al. (2015) found that the motivational commitment of determined people is high. Although perseverance and motivational stability seem to be internal grift concepts, one is considered as a dimension of temperament and personality and the other is known as part of the belief system (Park and Peterson, 2006; Lounsbury et al., 2009; Linley et al., 2010).

Teacher candidates are able to graduate after passing through various obstacles and passing through a long education and training process. This situation makes it necessary for the teacher candidates to make a constant struggle for life. It is possible to achieve resilience by motivating them to be successful through the determination and motivation they have in this struggle. The research findings also show that there is a positive relationship between the levels of resilience, tenacity and motivational stability of the prospective teachers. This will enable the training of more effective teachers with the programs to be made at the point of bringing the psychological stability to the prospective teachers.

In order to generalize the research results, studies can be carried out by including university students from different departments

\section{References}

Ahmet, A., Ö.A. Akdemir and İ. Seçer, 2015. Adaptation of teaching motivation scale to Turkish: Validity and reliability study. Current Research in Education, 1(1): 33-45.

Bostan, C.M., 2015. The role of motivational persistence and resilience over the well-being changes registered in time. Symposion, 2(2): $215-$ 241.Available at: https://doi.org/10.5840/symposion20 152212 .

Breen, R. and R. Lindsay, 2002. Different disciplines require different motivations for student success. Research in Higher Education, 43(6): 693-725.Available at: 10.1023/A:1020940615784.

Brennen, A.M., 2006. Enhancing students' motivation. Available from http://www.soencouragement.org/enhancing-studentsmotivation.htm [Accessed March 1, 2018].

Calik, F., 2014. Examination of leisure motivation and students to participate in leisure activities in terms of various variables. International Online Journal of Educational Sciences, 6(2): 361-372.Available at: https://doi.org/10.15345/iojes.2014.02.010.

Celik, I., 2015. Social emotional learning skills and educational stress. Educational Research and Reviews, 10(7): 799-803.Available at: https://doi.org/10.5897/err2015.2114.

Celik, İ. and H. Sarıçam, 2018. The relationships between academic locus of control, positive thinking skills and grit in high school students. Universal Journal of Educational Research, 6(3): 392-398.Available at: https://doi.org/10.13189/ujer.2018.060305.

Celik, İ., H. Sarıçam and S. Sönmez, 2018. The relationships between strengths self-efficacy, resilience, and grit. International Science and Education.Available at: 10.13140/RG.2.2.30812.90247.

Deci, E.L. and R.M. Ryan, 1985. Intrinsic motivation and self-determination in human behavior. New York: Plenum.

Demirel, İ.N., 2009. Knowledge levels of agri provincial directors of national education on the issue of motivating education leader to common objectives. Humanity and Social Sciences Journal, 4(2): 12 1-129.

Duckworth, A., C. Peterson, M. Matthews and D. Kelly, 2007. Grit: Perseverance and passionfor long-term goals. Journal of Personality and Social Psychology, 92(6): 1087-1 101.Available at: https://doi.org/10.1037/0022-35 14.92.6.1087.

Karairmak, O., 2006. Resilience, risk and protective factors. Turkish Psychological Counseling and Guidance Journal, 3(26): 129-142.

Keye, M.D. and A.M. Pidgeon, 2013. An investigation of the relationship between resilience, mind fulness, and academic self-efficacy. Open Journal of Social Sciences, 1(6): 1-4.Available at: https://doi.org/10.4236/jss.2013.16001.

Linley, P.A., K.M. Nielsen, R. Gillett and R. Biswas-Diener, 2010. Using signature strengths in pursuit of goals: Effects on goal progress, need satisfaction, and well-being, and implications for coaching psychologists. International Coaching Psychology Review, 5(1): 615.

Lounsbury, J.W., L.A. Fisher, J.J. Levy and D.P. Welsh, 2009. An investigation of character strengths in relation to the academic success of college students. Individual Differences Research, 7(1): 52-69.

Masten, A., 1986. Humor and competence in school-aged children. Child Development, 57(2): 461-473.Available at: https://doi.org/10.1111/j.1467-8624.1986.tboo045.x.

Park, N. and C. Peterson, 2006. Methodological issues in positive psychology and the assessment of character strengths. In A. D. Ong\& M. vanDulmen (Eds.), Handbook of methods in positivepsychology. New York: Oxford UniversityPress. pp: 292-305.

Pew, S., 2007. Andragogy and pedagogy as foundational theory for student motivation in higher education. In Sight: A Journal of Scholarly Teaching, 2(unknown): 14-25. 
Raphiphatthana, B., P. Jose and K. Salmon, 2018. Does dispositional mindfulness predict the development of grit? Journal of Individual Differences, 39(2): 76-87.Available at: https://doi.org/10.1027/1614-0001/a000252.

Reraki, M., I. Celik and H. Saricam, 2015. Grit as a mediator of the relationship between motivation and academic achievement. Ozean Journal of Social Science, 8(1): 19-32.Available at: 10.13140/RG.2.2.15063.78240.

Rutter, M., 2006. Implications of resilience concepts for scientific understanding. Annals of the New York Academy of Sciences, 1094(1): 112.Available at: https://doi.org/10.1196/annals.1376.002.

Ryan, R.M. and E.L. Deci, 2000. Intrinsic and extrinsic motivations: Classic definitions and new directions. Contemporary Educational Psychology, 25(1): 54-67.Available at: https://doi.org/10.1006/ceps.1999.1020.

Sariçam, H., 2015. Academic locus of control and motivational persistence: Structural equation modeling. Journal of Educational Sciences Research, 5(1): 79-92.Available at: http://dx.doi.org/10.12973/jesr.2015.51.5.

Saricam, H., A. Akın, Ü. Akın and A.B. İlbay, 2014. Turkish form of motivational stability scale: Validity and reliability study. Turkish Journal of Education, 3(1): 60-69.

Sarıçam, H., İ. Celik and A. Ŏguz, 2016. Turkish adaptation of the short grit scale (Grit-S): Validity and reliability study. International Journal of Turkish Literature Culture Education, 5(2): 927-935.Available at: 10.7884/Teke.622.

Sarıçam, H., A.B. Ilbay, R. Uysal, M. Cardak and A. Akın, 2012. Turkish version of the Short form of Resilience Appraisal Scale: Thevalidity and reliabilitystudy. Paper Presented at the International Counseling and Education Conference 2012 (ICEC 2012), May, 3-5, Istanbul, Turkey.

Sarıçam, H. and B. Kırgıl, 2013. The investigation of the relationship between the teachers' levels of well-being and motivational. IV. Forum of Educational Administration (EYFOR-IV), 3-5 Ekim 2013, Balıkesir, Turkey.

Sarıçam, H. and G. Yetim, 2016. The relationship between emotional intelligence and resilience in pre-school teachers. 3rd International Eurasian Educational Research Congress 31 May - 03 June 2016, Mugla, Turkey.

Soyer, F., Y. Can, H. Güven, G. Hergüner, M. Bayansalduz and B. Tetik, 2010. Investigation of relation between motivation of success and team unity of sportsmen. Journal of Human Sciences, 7(1): 225-239. 